\title{
Penanaman Karakter Sadar Lingkungan Melalui Program Adiwiyata di MIM Potronayan 2 Boyolali
}

\author{
Tri Nur Wahyudi ${ }^{1}$, Dedy Prasetyo ${ }^{2}$, Adnan Dwi Prasetyo ${ }^{3}$, Rinawati ${ }^{4}$, Indah Kusumawati ${ }^{5}$, Ummi \\ Uswatun Hasana $^{6}$, Femilia Anggun Ashari ${ }^{7}$, Dhanis Resty Aisyah ${ }^{8}$, Rika Anggraini ${ }^{9}$, Twine Levia \\ Gistiani $^{10}$ \\ 1,2,3,4,5,6,7,8,9,10 Fakultas Keguruan dan Ilmu Pendidikan, Universitas Muhammadiyah Surakarta, Indo- \\ nesia
}

\section{INFORMASI ARTIKEL}

\section{Histori Artikel:}

Submit: 18 Mei 2020

Revisi: 1 Juni 2020

Diterima: 25 Juni 2020

Publikasi: 30 Juni 2020

Periode Terbit: Juli 2020

\section{Kata Kunci:}

implementasi,

pengetahuan lingkungan,

program Adiwiyata

\section{Correspondent Author:}

Dedy Prasetyo

Fakultas Keguruan dan Ilmu Pendidikan

Universitas Muhammadiyah Surakarta,

Indonesia

Email: dediprasetyo207@gmail.com

\begin{abstract}
ABSTRAK
Kesadaran menjaga lingkungan sekitar merupakan salah satu karakter yang harus ditanamkan kepada anak sejak dini. Salah satu usaha yang dapat dilakukan dengan melaksanakan Program Adiwiyata di sekolah. Program Adiwiyata merupakan salah satu program yang mengajarkan siswa untuk peduli dan sadar akan pentingnya menjaga lingkungan. Berdasarkan pemaparan di atas, lebih lanjut tertarik untuk melakukan pengabdian masyarakat berupa implementasi program Adiwiyata di sekolah. Tujuan pengabdian masyarakat ini untuk meningkatkan pengetahuan siswa mengenai lingkungan di MIM Potronayan 2. Pengabdian masyarakat ini menggunakan metode pendidikan masyarakat yang difokuskan pada warga sekolah terutama para siswa di MIM Potronayan 2. Hasil pengabdian masyarakat ini menunjukkan bahwa implementasi Adiwiyata di MIM Potronayan 2 menunjukkan perubahan yang cukup signifikan. Siswa yang awalnya kurang paham mengenai pentingnya menjaga lingkungan sekitar menjadi lebih tahu dan menyadari betapa pentingnya menjaga lingkungan sekitar mereka. Hal ini dapat dilihat dari antusias para siswa dalam menjaga tanaman yang telah mereka tanam dan juga kesadaran mereka untuk membuang sampah pada tempatnya. Oleh karena itu, program Adiwiyata merupakan salah satu program yang sangat baik untuk dilaksanakan di sekolah sebagai salah satu usaha penanaman karakter cinta lingkungan sejak dini.
\end{abstract}

\section{Pendahuluan}

Pada era modern ini, lingkungan menjadi salah satu topik yang perlu mendapat perhatian dari masyarakat. Berdasarkan Undang-Undang mengenai Pengelolaan Lingkungan Hidup Nomor 32 tahun 2009, "Lingkungan Hidup adalah kesatuan ruang dengan semua benda, daya, keadaan, dan makhluk hidup termasuk manusia dan perilakunya yang mempengaruhi kelangsungan peri kehidupan dan kesejahteraan manusia serta makhluk hidup lain" (Siahaan, 2004)(Siahaan, 2014). Namun, lingkungan saat ini lambat laun mulai terancam oleh berbagai dampak yang ditimbulkan aktivitas manusia. Cara hidup yang salah dalam menilai lingkungan merupakan salah satu aspek yang mengakibatkan terjadinya kerusakan lingkungan. Perubahan iklim yang sangat ekstrem seperti curah hujan yang terlalu tinggi, kemarau panjang, dan meningkatnya suhu udara merupakan beberapa dampak yang harus ditanggung oleh manusia saat ini (Permana \& Ulfatin, 2018).

Kerusakan lingkungan, sebagian besar merupakan dampak dari ulah manusia yang selalu merasa kurang dan tak pernah puas dengan apa yang telah tersedia di sekitar mereka (Iswari \& Utomo, 2017). Untuk memenuhi kebu- 


\section{doi: 10.23917/bkkndik.v2i1.10794}

tuhan hidup yang begitu beragam, terkadang manusia melakukan eksploitasi sumber daya alam dengan sangat berlebih, sehingga lupa akan dampak yang ditimbulkan oleh kegiatan tersebut. Kurangnya pengetahuan serta kepedulian manusia mengenai lingkungan, menjadi salah satu faktor utama yang menyebabkan terjadinya kerusakan lingkungan saat ini.

Seiring dengan banyaknya permasalahan mengenai lingkungan, pendidikan karakter terutama mengenai kepedulian terhadap lingkungan menjadi salah satu hal yang mendapat perhatian oleh masyarakat dan pemerintah (Narimo, et al., 2018). Pendidikan berbasis karakter cinta lingkungan dianggap sangat penting dikembangkan di sekolah, baik sekolah dasar, menengah, maupun atas. Pemerintah melalui Kementerian Pendidikan juga menginstruksikan agar setiap sekolah menerapkan pendidikan karakter, sehingga diharapkan siswa nantinya memiliki karakter yang sesuai dengan nilai, norma, dan agama yang berlaku di masyarakat (Bahrudin, 2017; Arisona, 2018; Prabowo \& Sidi, 2010; Sabardila et al., 2019).

Dalam penguatan pendidikan karakter khususnya di bidang lingkungan ini seharusnya diberikan sejak usia dini dengan tujuan nilai karakter yang tertanam pada anak bisa dijalankan secara terbiasa tanpa beban. Hal ini sejalan dengan kerangka pendidikan untuk pembangunan berkelanjutan atau Education for Sustainable Development (ESD) (Prabawani, Hanika, Pradhanawati, \& Budiatmo, 2017). Serta program pendidikan karakter peduli lingkungan ini bisa diterapkan di sekolah dengan berhasil jika diintegrasikan dengan visi, misi sekolah dan mata pelajaran yang diberikan serta didukung oleh semua stakeholder (Riyanti \& Maryani, 2019). Program yang diterapkan disekolah biasanya berdasarkan; kebijakan berwawasan lingkungan; pelaksanaan kurikulum berbasis lingkungan; kegiatan lingkungan berbasis partisipatif dan pengelolaan sarana pendukung ramah lingkungan sehingga bisa meningkatkan kualitas sekolah itu sendiri (Pradini, Sujanto \& Nurjannah, 2018). Namun demikian berdasarkan penelitian Meilinda, Prayitno, Karyanto (2017) tingkat literasi lingkungan atau yang disebut sekolah hijau (green school) pada sekolah-sekolah di Surakarta dan sekitarnya masih rendah. Hal tersebut dilihat dari aspek pengetahuan, kepedulian dan keteladan. Oleh karena itu diperlukan adanya upaya untuk membangun karakter peduli lingkungan di lingkungan sekolah.
Berdasarkan uraian di atas, penulis tertarik untuk melaksanakan program yang bernama Program Adiwiyata. Program Adiwiyata merupakan program yang bertujuan untuk mendorong dan membentuk sekolah peduli dan berbudaya lingkungan sebagai upaya pelestarian lingkungan sekitar (Landriany, 2014). Selain itu, Adiwiyata merupakan suatu program yang sangat cocok untuk diterapkan di sekolah karena dalam dunia pendidikan penerapan tersebut akan lebih mudah diterima serta diterapkan (Rahmah, 2014). Disisi lain kegiatan ini dapat dijadikan upaya untuk pencegahan terhadap degradasi lingkungan di abad 21 (Jabłońska, 2017).

Dalam implementasi program Adiwiyata perguruan tinggi dapat menjadi agent of change di lingkungan sekolah melalui salah satu tri darma perguruan tinggi yakni pengabdian masyarakat. Diharapkan dengan diadakannya Program Adiwiyata di MIM Potronayan 2 Boyolali, Jawa Tengah dapat meningkatkan pengetahuan dan kesadaran siswa mengenai pentingnya menjaga lingkungan sekitar.

Tujuan diadakannya pengabdian masyarakat ini adalah untuk meningkatkan pengetahuan siswa mengenai lingkungan di MIM Potronayan 2. Dengan demikian, penulis dapat mengetahui minat serta apresiasi siswa dalam mengikuti program Adiwiyata, sehingga kami dapat mengetahui bagaimana peningkatan pengetahuan siswa mengenai lingkungan sekitar. Hal ini, terutama mengenai bagaimana apresiasi mereka dalam menanam tanaman dan merawatnya, kesadaran siswa untuk membuang sampah pada tempatnya, dan bagaimana cara memilah sampah sesuai dengan jenisnya.

\section{Metode Pelaksanaan}

Pengabdian masyarakat ini menggunakan metode pendidikan masyarakat. Pendidikan masyarakat lebih difokuskan pada warga sekolah terutama siswa di MIM Potronayan 2. Metode ini dilaksanakan dengan cara terjun langsung bersama warga sekolah untuk melakukan penghijauan sekolah dengan melakukan penanaman tanaman di lingkungan sekitar sekolah. Selain itu, juga melakukan sosialisasi kepada siswa mengenai pentingnya membuang sampah pada tempatnya dan memisahkan sampah sesuai dengan jenisnya. Guna mendukung pemilahan jenis sampah tersebut, dilakukan pengadaan tong sampah organik dan anorganik sebagai usaha memudahkan siswa dalam membedakan jenis sampah. Pengabdian ini difokuskan kepada siswa sebagai objek 
dalam pengabdian ini. Selain itu, juga melibatkan bapak dan ibu guru untuk turut berpartisipasi membantu mendampingi dan mengarahkan siswa.

\section{Hasil Pelaksanaan dan Pembahasan}

Pendidikan merupakan suatu tempat untuk menanamkan ilmu pengetahuan maupun menumbuhkan karakter positif setiap individu. Tidak hanya pengetahuan mengenai mata pelajaran, melainkan juga pengetahuan mengenai hal-hal di sekitar, yaitu lingkungan. Upaya meningkatkan pengetahuan siswa mengenai lingkungan sekitar dapat dilakukan dengan beberapa cara. Salah satu caranya yaitu melalui Program Adiwiyata. Seperti yang telah dipaparkan sebelumnya, Adiwiyata merupakan upaya penghijauan sekolah dan sosialisasi kepada siswa mengenai pentingnya menjaga kelestarian lingkungan di sekolah.

Implementasi program Adiwiyata yang dilaksanakan di MIM Potronayan 2 dilakukan melalui beberapa kegiatan. Kegiatan-kegiatan tersebut diantaranya yaitu penanaman tanaman di sekitar lingkungan sekolah yang dilakukan oleh seluruh warga sekolah, sosialisasi mengenai pentingnya menjaga lingkungan sekitar terutama sekolah, dan pengadaan tong sampah bergambar.

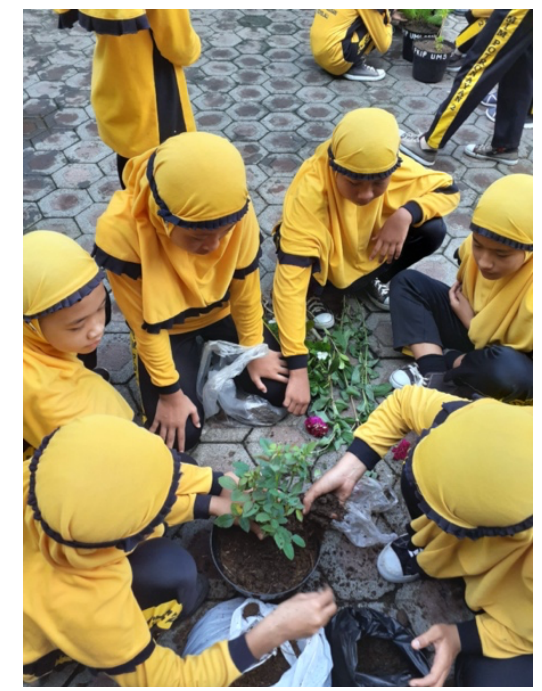

Gambar 1. Penanaman Tanaman Bersama

Pada gambar 1 di atas, menunjukkan proses dari kegiatan penanaman tanaman bersama di lingkungan sekitar sekolah. Pada kegiatan tersebut, seluruh siswa diminta untuk membawa tanaman, tanah, dan pupuk. Untuk tempat tanaman, disediakan beberapa pot tanaman untuk setiap kelas. Pada kegiatan penanaman, siswa diminta untuk menanam tanaman tersebut secara berkelompok sesuai dengan kelasnya masing-masing. Guru ikut serta dalam mendampingi dan mengarahkan siswa. Dengan adanya kegiatan menanam tanaman ini, diharapkan para siswa mampu menjaga dan merawat tanaman yang telah mereka tanam. Sehingga, siswa menjadi lebih dekat dan peduli dengan tanaman-tanaman dan keadaan lingkungan sekitar mereka terutama lingkungan sekolah.

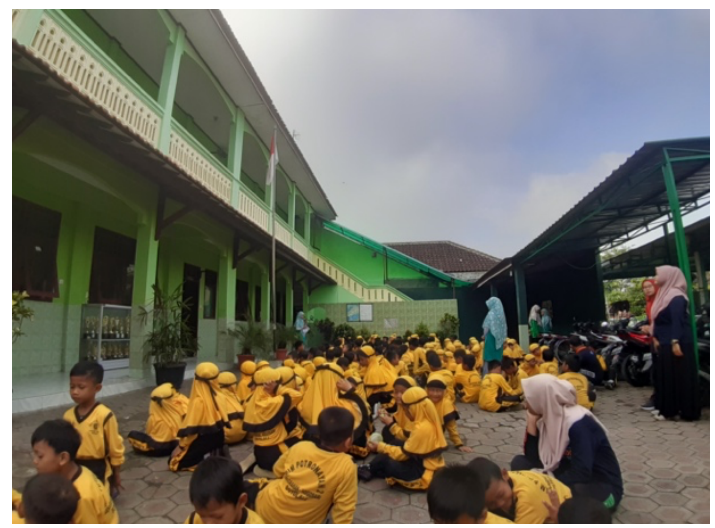

Gambar 2. Sosialisasi Jenis Sampah

Pada kegiatan selanjutnya yaitu pada gambar 2, diadakan sosialisasi mengenai pentingnya menjaga lingkungan sekitar terutama sekolah. Salah satunya yaitu mengenai pentingnya membuang sampah pada tempatnya. Selain memberikan sosialisasi mengenai pentingnya membuang sampah pada tempatnya, juga memberikan pengarahan kepada siswa tentang pengelompokan jenis sampah organik dan anorganik. Melalui kegiatan sosialisasi ini, diharapkan siswa dapat membedakan antara jenis sampah organik dan organik. Selain itu, diharapkan para siswa juga mampu menerapkannya dalam kehidupan sehari-hari.

Gambar 3 di bawah merupakan salah satu contoh tong sampah bergambar yang dibuat. Kegiatan pengadaan tong sampah bergambar dengan tujuan untuk menarik perhatian siswa supaya membuang sampah pada tempatnya. Selain itu, pengadaan tong sampah tersebut juga diharapkan mampu memudahkan para siswa dalam membuang sampah sesuai dengan jenisnya. Hal ini dikarenakan pada tong sampah tersebut telah bertuliskan tempat sampah organik dan mana tempat sampah anorganik.

Hasil implementasi program Adiwiyata yang dilaksanakan di MIM Potronayan 2 ini, dapat dikatakan menunjukkan hasil yang cukup signifikan. Hal ini dikarenakan para siswa yang sangat antusias dalam mengikuti seluruh kegiatan yang ada dalam program Adi- 
wiyata. Selain antusias para siswa yang sangat tinggi, dukungan dari para guru juga sangat berpengaruh terhadap keberhasilan program ini. Para siswa yang awalnya kurang paham mengenai bagaimana cara menanam dan merawat tanaman, menjadi lebih paham bagaimana cara menanam dan menjaga tanaman yang ada di sekitar mereka.

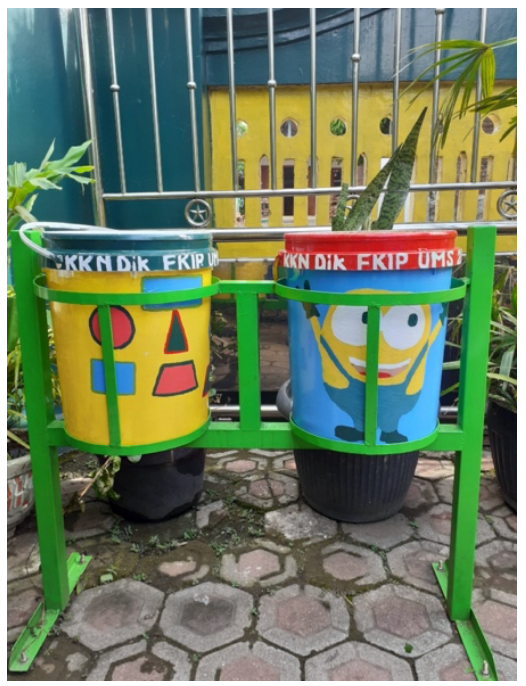

Gambar 3. Pengadaan Tong Sampah Bergambar

Selain itu, mereka yang awalnya tidak tahu mengenai jenis-jenis sampah kini menjadi tahu jenisjenis sampah yang termasuk dalam sampah organik dan anorganik. Siswa yang awalnya kurang memperhatikan tanaman-tanaman yang ada di lingkungan sekolah juga menjadi lebih sadar untuk menjaga tanaman yang telah mereka tanam dengan menyiraminya setiap pagi. Hal ini berdampak pada lingkungan sekolah yang menjadi tampak lebih asri dan nyaman ketika proses pembelajaran. Hasil kegiatan sosialisasi pengelompokan jenis sampah juga sangat terlihat signifikan. Hal ini dapat dilihat dari para siswa yang awalnya masih sering membuang sampah sembarangan menjadi lebih sadar dengan membuang sampah para tempatnya. Selain itu, juga mulai bisa untuk membedakan jenis sampah dan membuang sampah sesuai dengan jenisnya. Dengan adanya kegiatan Adiwiyata ini akan tertanam jiwa kebiasaan kebersihan lingkungan dan kelestarian lingkungan yang sejuk yang dapat mendukung kegiatan belajar di sekolah (Zaenuri, Sudarmin, Utomo \& Juul, 2017).

Program Adiwiyata yang dilakukan memiliki beberapa kelebihan dan kekurangan. Beberapa kelebihan yang terdapat dalam program Adiwiyata ini yaitu:
1. Menjadikan sekolah tampak lebih asri.

2. Beberapa lahan sekolah yang awalnya tampak kosong menjadi lebih bermanfaat karena diisi dengan tanaman-tanaman.

3. Siswa tahu perbedaan antara sampah organik dan anorganik.

4. Pengadaan tong sampah yang bergambar membuat siswa lebih mudah dalam membuang sampah sesuai dengan jenisnya.

Selain kelebihan yang telah dipaparkan di atas, ada juga beberapa kekurangan yang terdapat dalam program Adiwiyata ini, diantaranya:

1. Masih ada beberapa siswa yang belum membawa media tanam seperti tanah dan pupuk.

2. Kurang tersedianya alat berkebun seperti sekop, cangkul, dan sebagainya.

\section{Simpulan}

Implementasi dari program Adiwiyata yang dilakukan di MIM Potronayan 2, Boyolali, Jawa Tengah cukup memberikan dampak yang positif bagi siswa. Dengan adanya program Adiwiyata ini, para siswa yang awalnya kurang mengetahui mengenai cara merawat tanaman dan pengelompokan jenis sampah menjadi lebih mengetahui dan sadar akan pentingnya menjaga lingkungan sekitar terutama sekolah. Selain itu, program Adiwiyata yang sebagai usaha untuk meningkatkan kesadaran siswa mengenai pentingnya menjaga lingkungan sekitar terutama pada era pemanasan global saat ini. Dengan adanya program Adiwiyata ini, dapat disimpulkan bahwa program Adiwiyata dapat meningkatkan pengetahuan siswa mengenai lingkungan di MIM Potronayan 2. Diharapkan program Adiwiyata ini dapat berlanjut dan menjadi program rutin di MIM Potronayan 2, Boyolali, Jawa Tengah. Hal ini, dikarenakan program Adiwiyata merupakan salah satu program yang diyakini dapat menumbuhkan karakter peduli lingkungan kepada siswa.

\section{Daftar Pustaka}

Arisona, R. D. (2018). Pengelolaan Sampah 3r (Reduce, Reuse, Recycle) pada Pembelajaran IPS untuk Menumbuhkan Karakter Peduli Lingkungan. Al Ulya, 3(I), 39-5l.

Bahrudin, M. D. F. (2017). Pelaksanaan program Adiwiyata dalam mendukung pembentukan karakter peduli lingkungan di SMA Negeri 4 Pandeglang. Jurnal Pendidikan Geografi, 17(1), 
$25-37$.

Iswari, R. D., \& Utomo, S. W. (2017). Evaluasi Penerapan Program Adiwiyata Untuk Membentuk Perilaku Peduli Lingkungan di Kalangan Siswa (Kasus: SMA Negeri 9 Tangerang Selatan dan MA Negeri 1 Serpong). Jurnal Ilmu Lingkungan Undip, $15(1), 35-41$.

Landriany, E. (2014). Implementasi kebijakan adiwiyata dalam upaya mewujudkan pendidikan lingkungan hidup di SMA Kota Malang. Jurnal Kebijakan Dan Pengembangan Pendidikan, 2(1).

Narimo, S., Maryadi, M., Fatoni, A., Anif, S., Sumardjoko, B., \& Adhantoro, M. S. (2018, November). Pancasila and Citizens Education (PKn) Learning Based on Local Culture in The Establishment of Student Characters. In Profunedu International Conference Proceeding (Vol. 1, pp. 255-260)

Permana, B. I., \& Ulfatin, N. (2018). Budaya sekolah berwawasan lingkungan pada sekolah adiwiyata mandiri. Ilmu Pendidikan: Jurnal Kajian Teori Dan Praktik Kependidikan, 3(1), 11-21.

Prabowo, A., \& Sidi, P. (2010). Memahat Karakter Melalui Pembelajaran Matematika. Proceedings of The 4th International Conference on Teacher Education, 165-177. Bandung: UPI \& UPSI.

Rahmah, Y. D. (2014). Implementasi Program Sekolah Adiwiyata (Studi pada Sekolah Dasar Negeri Manukan Kulon III/540 Kota Surabaya). Jurnal Administrasi Publik, 2(4), 453-757.

Sabardila, A., Budiargo, A. D., Wiratmoko, G., Himawa, J. A., Triutami, A., Intansari, A., ... Suistri. (2019). Pembentukan Karakter Peduli Lingkungan melalui Kegiatan Penghijauan pada Siswa. 1(2), 35-41. https://doi.org/10.23917/bkkndik.vli2.10763

Siahaan. (2014). Hukum Lingkungan dan Ekologi Pembangunan. Jakarta: Erlangga.
Siahaan, N. H. T. (2004). Hukum lingkungan dan ekologi pembangunan. Erlangga. 